\title{
Is Focal Cortical Dysplasia/Epilepsy Caused by Somatic MTOR Mutations Always a Unilateral Disorder?
}

Renzo Guerrini, MD, FRCP, Mara Cavallin, MD, PhD, Tommaso Pippucci, PhD, Anna Rosati, MD, PhD, Francesca Bisulli, MD, Paola Dimartino, MSc, Carmen Barba, MD, PhD, Rita Garbelli, PhD, Anna Maria Buccoliero, MD, PhD, Laura Tassi, MD, and Valerio Conti, PhD

Neurol Genet 2021;7:e540. doi:10.1212/NXG.0000000000000540

\section{Abstract}

\section{Objective}

To alert about the wide margin of unpredictability that distribution of somatic MTOR mosaicism may have in the brain and the risk for independent epileptogenesis arising from the seemingly healthy contralateral hemisphere after complete removal of epileptogenic focal cortical dysplasia (FCD).

\section{Methods}

Clinical, EEG, MRI, histopathology, and molecular genetics in 2 patients (1 and 2) treated with focal resections and subsequent complete hemispherectomy for epileptogenic FCD due to somatic MTOR mutations. Autoptic brain study of bilateral asymmetric hemispheric dysplasia and identification of alternative allele fraction (AAF) rates for AKT1 (patient 3).

\section{Results}

The strongly hyperactivating p.Ser2215Phe (patient 1) and p.Leu1460Pro (patient 2) MTOR mutations were at low-level AAF in the dysplastic tissue. After repeated resections and eventual complete hemispherectomy, both patients manifested intractable seizures arising from the contralateral, seemingly healthy hemisphere. In patient 3, the p.Glu17Lys AKT1 mutation exhibited random distribution and AAF rates in different tissues with double levels in the more severely dysplastic cerebral hemisphere.

\section{Conclusions}

Our understanding of the distribution of somatic mutations in the brain in relation to the type of malformation and its hypothesized time of origin may be faulty. Large studies may reveal that the risk of a first surgery being disappointing might be related more to the specific somatic mammalian target of rapamycin mutation identified than to completeness of resection and that the advantages of repeated resections after a first unsuccessful operation should be weighed against the risk of the contralateral hemisphere becoming in turn epileptogenic.

\author{
Correspondence \\ Prof. Guerrini
}

r.guerrini@meyer.it 


\section{Glossary}

AAF = alternative allele fraction; AED = antiepileptic drug; DMEG $=$ dysplastic megalencephaly; FCDII $=$ focal cortical dysplasia type II; HME = hemimegalencephaly; $\mathbf{M C D}$ = malformations of cortical development; $\mathbf{M E G}=$ megalencephaly; mTOR = mammalian target of rapamycin; OFC = occipital frontal circumference (head circumference); smMIP = singlemolecule molecular inversion probe; WES = whole-exome sequencing.

Mammalian target of rapamycin (mTOR) pathway is a key regulator of cell growth, proliferation, survival, autophagy, transcription, and protein synthesis. ${ }^{1}$ Constitutional and somatic mutations of genes within this pathway, including AKT1, AKT3, DEPDC5, MTOR, NPRL2/3, PIK3CA, $P I K 3 R 2$, and TSC1/2, have been associated with a phenotypic continuum of malformations of cortical development (MCD), ranging from focal cortical dysplasia type II (FCDII) to megalencephaly (MEG)/dysplastic megalencephaly (DMEG). ${ }^{2-5}$ Alternative allele fraction (AAF) and mutation distribution influence the phenotype. Low-level somatic mutations have mainly been associated with FCDII, intermediate-level somatic mutations affecting a single hemisphere with larger brain malformations such as hemimegalencephaly (HME), and high-level somatic mutations affecting multiple organs (systemic mosaicism) and constitutional mutations with MEG/DMEG. ${ }^{2-4}$

About 79\% of mutated FCDII patients exhibit brain mosaic rates lower than $5 \%{ }^{6}$ Of the remaining patients in whom a mutation is found in the dysplastic tissue, $50 \%$ exhibit mosaic rates ranging from $6.5 \%$ to $18.6 \%$ and $50 \%$ carry constitutional mutations. In about $41 \%$ of patients with FCDII, no causative mutations can be identified. ${ }^{6}$ Detection of somatic mosaicism in tissue specimens surgically removed based on abnormal structure and epileptogenicity does not reveal whether lower level mosaicism is present in remote, homolateral, or contralateral, normal-looking brain areas. However, around $62 \%$ of patients carrying constitutional mutations in DEPDC5, NPRL2, or NPRL3 have normal brain MRI. ${ }^{7}$

FCD-related epilepsy is often drug resistant. ${ }^{8}$ As complete as possible surgical removal of the dysplastic tissue ${ }^{8}$ and histologic findings ${ }^{9}$ influence postsurgery outcome, with about $60 \%-75 \%$ of patients operated with one or multiple focal resections or hemispherectomy $y^{7,10}$ achieving a good surgical outcome (Engel Class I or II). ${ }^{9,11}$ However, a poor outcome can be influenced by multiple factors, including incomplete resections, subtle FCD that escapes MRI detection, age at seizure onset, and duration of epilepsy. ${ }^{10}$ Genetic testing before surgery is advised in patients with $\mathrm{FCD}^{8}$ because constitutional mutations may occur in genes that influence the epileptogenic potential of the brain beyond the visible dysplasia. These include, for example, TSC1 and TSC2, which may manifest with a single tuber but also genes that are unrelated to MTOR, such as $S C N 1 A^{12}$ or CNTNAP2. ${ }^{13}$ The number of patients with FCD-associated constitutional or somatic mutations in mTOR pathway genes for whom data on epilepsy surgery outcome are available is restricted to a few carrying AKT3, DEPDC5, MTOR, NPRL2/3, PIK3CA, and TSC1/2 mutations. ${ }^{6,7,14}$ Knowledge originating from these observations is too preliminary, and until now, there have been no studies that have addressed if specific somatic mutations are associated with distinctive electroclinical characteristics and outcomes.

Here, we use different lines of evidence to highlight the unpredictable distribution of somatic mosaicism in the brain and the risk for delayed independent contralateral epileptogenesis despite concordant FCD and seizure onset zone before surgery. To this purpose, we use a combination of clinical, histopathologic, autoptic, and molecular genetic observations. Two patients with a long follow-up after focal resection and subsequent complete hemispherectomy for severely epileptogenic FCDII due to a somatic MTOR mutation developed intractable seizures arising from the contralateral hemisphere, which appeared structurally normal and devoid of epileptiform EEG activity before surgery. This outcome indicates that somatic mosaicism was likely present in the nonoperated hemisphere too, at a rate sufficient to precipitate epileptogenesis but not to cause an MRI visible malformation. Bilateral asymmetric cortical dysplasia may be related to uneven distribution between hemispheres of AAF, and we demonstrate this through an autoptic study of a brain harboring a somatic AKT1 mutation. These observations challenge conventional understanding of how somatic mutations distribute in the brain in relation to visible malformation and its supposed time of origin and should stimulate follow-up studies of individuals in whom somatic mosaicism is demonstrated after surgery. Data emerging from large studies may reveal that the risk of a first surgery being disappointing might turn out to be related more to the specific somatic mTOR mutation identified than to completeness of resection and that the advantages of repeated resections after a first unsuccessful operation should be weighted against the risk of the contralateral hemisphere becoming in turn epileptogenic.

\section{Methods}

\section{Study subjects}

Patients 1 and 2 belong to a small group of 4 patients followed up at Meyer Children's Hospital and Niguarda Hospital, in whom FCD and a somatic MTOR mutation were found in brain specimens after surgery. The remaining 2 patients, not discussed further in this report, are now aged 11 and 14.5 years and were operated with unilobar, incomplete resections 
at 5 and 13 years of age. They carried the p.Cys1483Tyr and p.Trp1456Gly mutations at 3\% and 7\% AAF rates and were classified as Engel outcome Class IVa and IIIa because of persisting homolateral seizures. Patient 1 had been included in a previous series with no detailed information on epilepsy follow-up. ${ }^{3}$ Patient 3, who exhibited a polymalformative Proteus-like syndrome, belonged to the larger cohort of consecutive patients in whom genetic testing had revealed either constitutional or somatic mutations in mTOR pathway genes seen at the Meyer Children's Hospital since 2010. This patient did not undergo epilepsy surgery but died prematurely and was studied at autopsy.

\section{Clinical evaluation, MRI studies, and EEG recordings}

For patients 1 and 2, we classified epileptic seizures according to the International League Against Epilepsy criteria ${ }^{15}$ and used the Engel Epilepsy Surgery Outcome Scale. ${ }^{11}$ We collected multiple 1.5 and $3 \mathrm{~T}$ brain MRI during follow-up and analyzed structural data using axial, coronal, and sagittal T1and T2-weighted and axial fluid-attenuated inversion recovery images. We recorded and analyzed multiple scalp video-EEG (international 10-20 electrode placement system) monitoring recordings.

\section{Genetic testing}

For patient 1, molecular methods for whole-exome sequencing (WES) and GS Junior amplicon sequencing-based confirmation of the variant have been previously reported. ${ }^{3}$ For patient 2, we extracted DNA from formalin-fixed paraffinembedded slides corresponding to lesional (FCDII) and nonlesional marginal tissues. We enriched DNA libraries for MTOR mutational hot spots associated with FCDII ${ }^{3,4,16-18}$ using single-molecule molecular inversion probes (smMIPs) and sequenced them on an Illumina MiSeq platform to obtain $>3,000 \mathrm{X}$ mean coverage of uncollapsed reads. We collapsed reads having the same single-molecule tag using MIPgen v1.0 (github.com/shendurelab/MIPGEN) and called somatic variants with VarScan (varscan.sourceforge.net/) v2.4.3. To validate candidate variants, we used the same methodology as the one used in a previous study. ${ }^{19}$ We designed targeted amplicon primers to contain Nextera adapters at $5^{\prime}$ followed by a molecular tag before the target complementary sequence, thus allowing to distinguish amplicons generated at each PCR cycle. Then, we sequenced pooled amplicons on the Illumina MiSeq platform with a theoretical coverage of about 10,000X and collapsed and analyzed sequences using the same bioinformatic pipeline used for SmMIP analysis, from FASTQ to Variant Call Format (VCF).

For patient 3, we analyzed DNA from multiple tissues sampled at autopsy, including cerebral hemispheres, cerebellum, multiple lipomas, spleen, liver, heart, and blood. We performed an mTOR genes panel analysis according to our previously published protocol ${ }^{20}$ and confirmed the percentage of mosaicism in the different tissues using the GS Junior amplicon sequencing-based approach. ${ }^{3}$

\section{Neuropathology}

We cut formalin-fixed, paraffin-embedded sections from dysplastic brain specimens resected during epilepsy surgery (patients 1 and 2) or examined at autopsy (patient 3) at 5- $\mu \mathrm{m}$ thickness and stained them with hematoxylin and eosin and thionin for histopathologic evaluation. We used additional sections of the most representative specimen of each case for immunohistochemical analysis performed using antibodies against neurofilaments (1:20; Zymed Laboratory, San Francisco, CA; PAN clone DA2; FNP7, RMb020.11), neuronal nuclei (1:100; Millipore, Billerica, MA), microtubuleassociated protein 2 (1:100, clone AP-20; Thermo Fisher Scientific, Waltham, MA), intermediate filament protein vimentin (1:100, clone V9; Dako, Carpinteria, CA), and phosphorylated ribosomal protein S6 (Ser240/244) (1:1,200; Cell Signaling Technology). We acquired images using an Eclipse 80i microscope with Digital Sight DS-U1 camera (Nikon Corporation, Tokyo, Japan).

\section{Standard protocol approvals, registrations, and patient consents}

The study was approved by the Pediatric Ethics Committees of the Tuscany Region (project RF-2013-02355240 Italian Ministry of Health and Tuscany Region). All participants or their parents/ legal guardians had signed informed consent to perform the procedures whose results are presented in this report.

\section{Data availability}

Data supporting the findings presented in this study but not provided in the article due to space limitations are available from the corresponding author on request from any qualified investigator, if in accordance with the Italian laws.

\section{Results}

\section{Patient 1}

Patient 1 is a 7-year-old girl born at 38 weeks of gestation from a bichorial-biamniotic twin pregnancy to healthy unrelated parents. Birth weight was 2,700 g (15th pc), length was $48 \mathrm{~cm}$ (50th pc), and head circumference (OFC) was $33 \mathrm{~cm}$ (25th pc). Apgar scores were 9-9. Her twin brother is healthy.

Her first seizures occurred at 3 months of life as staring with behavioral arrest, head and eye deviation to the left, right facial jerking, and asymmetric spasms, accompanied by left-sided ictal activity. Brain MRI showed an extensive cortical thickening and blurring of the cortical gray/white matter junction involving the entire left frontal lobe and fading in the parietal lobe, with ill-defined posterior borders (figure 1A). Seizures became soon very frequent and occurred as super-refractory status epilepticus, which prompted a left vertical parasagittal hemispherotomy ${ }^{21}$ at 6 months. Seizures relapsed soon after surgery with subcontinuous left epileptiform EEG activity (figure 1B). Several combinations of antiepileptic drugs (AEDs) were ineffective. A second operation was performed at 9 months, with left frontoparietal lobectomy. 


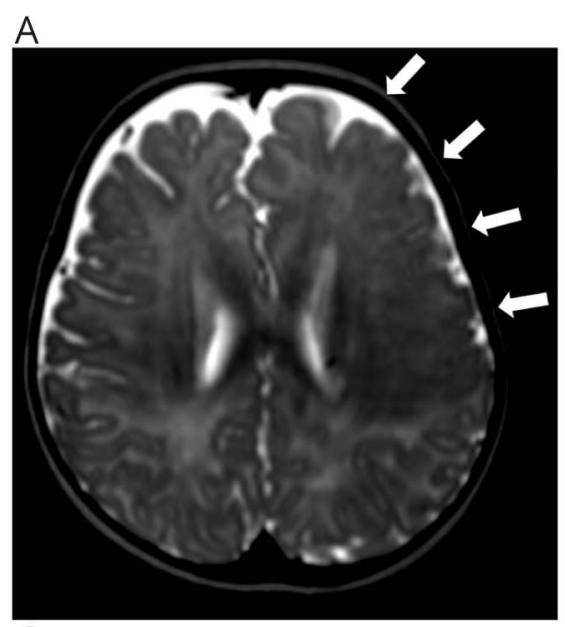

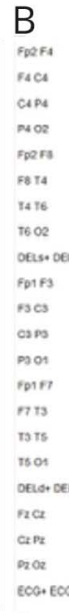

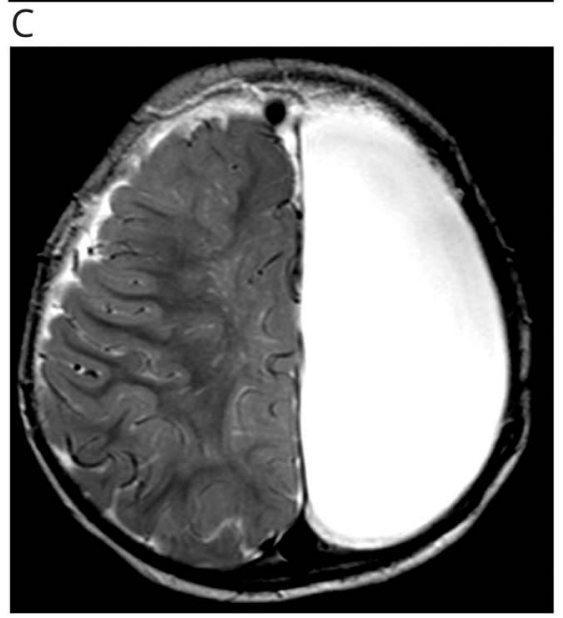

D

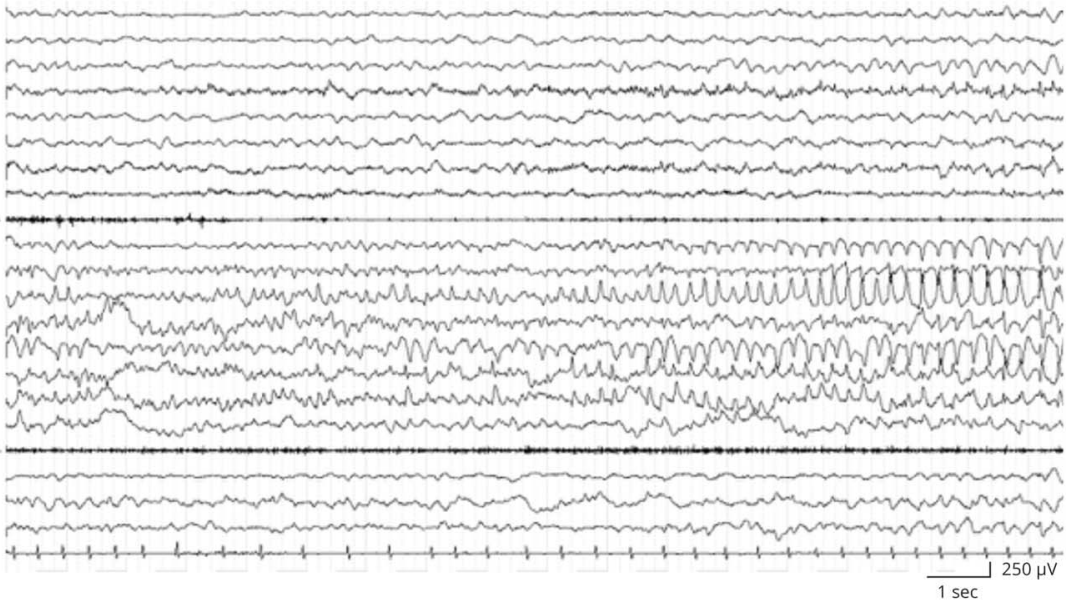

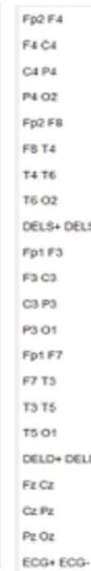

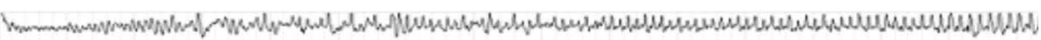
(n) Hen

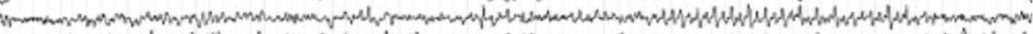

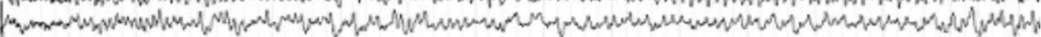

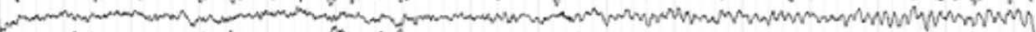

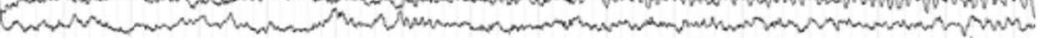

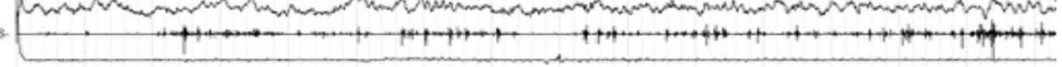
(1)

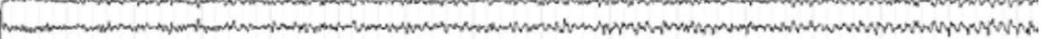
C) -

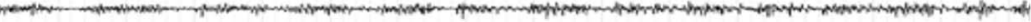
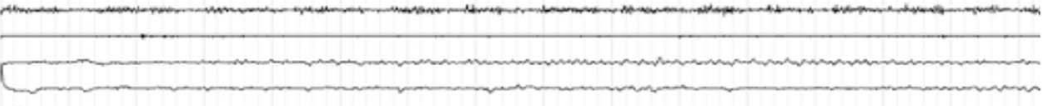

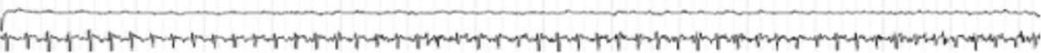
E $H \& E$

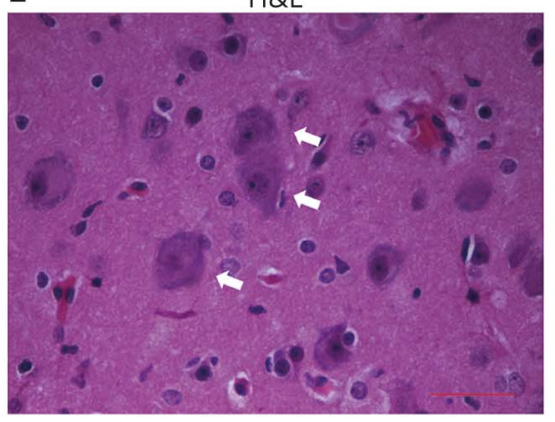

NF

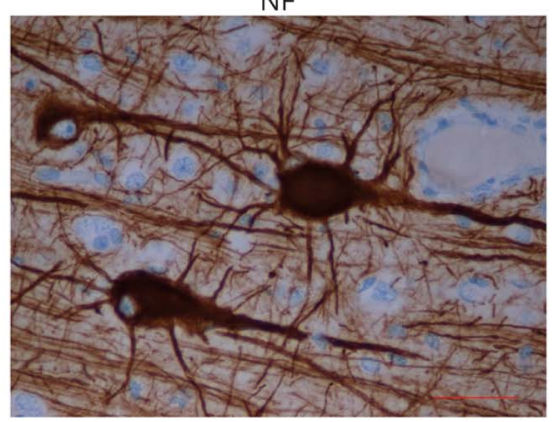

$\underset{1 \mathrm{sec}}{\longrightarrow} 200$

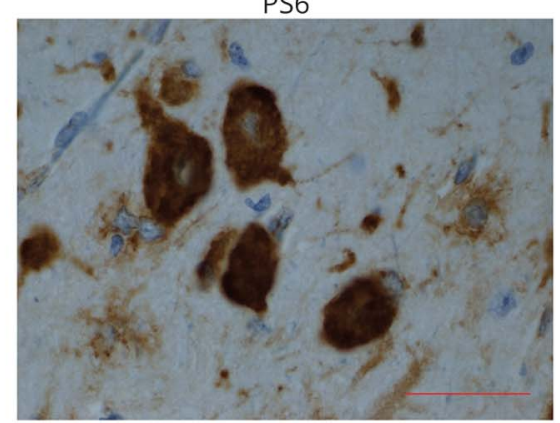

(A) Axial T2-weighted MRI section showing an extensive dysplastic area involving the entire left frontal lobe (arrows). (B) EEG recording at 6 months showing left frontocentral and anterior temporal ictal activity. (C) Axial T2-weighted MRI performed at 11 months after complete anatomic hemispherectomy. (D) EEG recorded at 15 months, showing build up of a right anterior frontal discharge. (E) Representative immunostaining of dysplastic brain tissue from the left frontal lobe. Hematoxylin-eosin (H\&E) staining shows dysmorphic neurons (white arrows). Phosphorylated RPS6 (PS6) staining demonstrates hyperactivation of the mammalian target of rapamycin pathway. Antineurofilament (NF) staining demonstrates neurofilament protein accumulation in dysmorphic neurons. Scale bar $=50 \mu \mathrm{m}$.

Neuropathology showed FCDIIa (figure 1E). After the procedure, seizures persisted unchanged, until completion of the left hemispherectomy (figure 1C), at 11 months of life, with placement of a ventriculoperitoneal shunt due to ensuing hydrocephalus.

Posthemispherectomy EEG showed low-voltage activity on the left and rhythmic sharp waves, never seen before, on the right. After 8-month seizure freedom, weekly polymorphic seizures reappeared with asymmetric tonic posturing, oroalimentary automatisms, eyes fluttering, and rightward ocular deviation, accompanied by right frontal ictal EEG activity (figure 1D). Several combinations of AEDs were ineffective.

After the last surgery, the girl experienced frequent episodes of refractory focal status epilepticus, each lasting several days, 
always originating from the right. Clinical examination showed severe intellectual disability, absent speech, axial hypotonia, right hemiplegia, and stereotypic movements. WES on brain-derived DNA revealed, the c.6644C $>\mathrm{T}$ (p.Ser2215Phe) MTOR mutation (NM_004958.3) at $~ 5.5 \%$ AAF (GS Junior sequencing validation: $\sim 2.46 \%$ ). The mutation was not present in blood and saliva. ${ }^{3}$

\section{Patient 2}

Patient 2 is an 8-year-old boy born at term, after an uncomplicated pregnancy to healthy unrelated parents. Birth weight was $3,410 \mathrm{~g}$ (50th pc), length was $51 \mathrm{~cm}(60 \mathrm{th} \mathrm{pc})$, and OFC was $35 \mathrm{~cm}$ (60th pc). Apgar scores were 9-10. During the first month of life, daily focal seizures appeared, with staring and tonic asymmetric posturing, accompanied by a right frontoparietal ictal discharge. At 3 months, asymmetric epileptic spasms also appeared. Brain MRI, at 1 month and 3 months, documented extensive blurring of the cortical graywhite matter junction involving the anterior right frontal lobe (figure 2A). Because of persisting seizures, at 15 months the child underwent a right frontopolar corticectomy. Neuropathology revealed FCDIIb (figure 2F).

Three months later, seizures reappeared with similar clinical and EEG features (figure 2, B and C). Subsequent parietal corticectomy with temporo-parieto-occipital disconnection only resulted in short seizure-free periods, with persisting right-sided origin, which prompted a complete right hemispherectomy at 5 years. After the operation, the child remained seizure free for 3 months, after which focal seizures relapsed as episodes of sleep arousal, with terrified facial expression and asymmetric posturing, accompanied by left frontotemporal ictal EEG activity (figure $2 \mathrm{E}$ ). Despite multiple AED combinations, daily seizures persisted over the years, manifested at times as status epilepticus. Outcome was classified as Engel Class IV. Follow-up MRI, at 8 years, showed the consequences of hemispherectomy, with a normal-appearing left hemisphere (figure 2D). The child has mild intellectual disability (Full-Scale IQ $=60$ ) with speech impairment and left surgery-induced hemiplegia.

After hemispherectomy, neuropathology identified residual dysplastic tissue, in which smMIPS analysis revealed the c.4379T >C (p.Leu1460Pro) MTOR mutation ${ }^{3,17}$ at $\sim 4.07 \%$ AAF (amplicon sequencing-based validation: $\sim 2.29 \%$ ). The mutation was not found in anatomic brain areas which appeared structurally normal in blood and skin.

\section{Patient 3}

Patient 3, a boy, was born at 37th gestational weeks by caesarian section to healthy unrelated parents. Level 2 fetal ultrasound showed macrocephaly, confirmed by fetal MRI at 37 weeks of gestation, associated with ventricular enlargement.

Growth parameters, at birth, were at the 85th pc for weight $(3,580 \mathrm{~g})$, between the 25th and 50th pc for length $(49 \mathrm{~cm})$, and $>90$ th $\mathrm{pc}$ for OFC $(42 \mathrm{~cm})$. Apgar scores were 8-9. The child exhibited dysmorphic features suggestive of a Proteuslike syndrome, including macrocephaly, splanchnocranium, and severe craniofacial asymmetry with right eye buphthalmos and left eye microphthalmia, severe arthrogryposis of the 4 limbs, skin hypertrophy, and dyschromic patches on both feet. Brain MRI, at 2 months, showed dysplastic asymmetric MEG, more severe on the right, with extensive areas of polymicrogyria, thin corpus callosum with cavum septi, and hydrocephalus with bilateral asymmetric ventricular enlargement (figure 3). Clinical examination showed severe axial hypotonia, spastic quadriplegia, cortical blindness, and failure to thrive. Neurologic development remained profoundly impaired with virtually no acquisitions. Ventriculocisternostomy was performed at 3 and 5 months to treat hydrocephalus. Since age 3 months, asymmetric spasms and tonic seizures appeared. EEG showed asymmetrical, right predominant burst-suppression activity. At the age of 6 years, the child died because of aspiration pneumonia.

At autopsy, macroscopic brain inspection confirmed the enlargement of the right hemisphere with ventricular dilatation and thinning of the brain parenchyma. Histopathology showed diffuse cortical dyslamination, more severe on the right, and neuronal depletion. Some neurons appeared cytomegalic, with disarrayed extensions and exhibited neurofilament protein accumulation (figure 3). Genetic testing revealed the c.49G>A (p.Glu17Lys) AKT1 mutation, ${ }^{22}$ variably distributed in the tissues analyzed as determined by multiple samples, averaging $35.6 \%$ in the right cerebral hemisphere and $16.26 \%$ in the left hemisphere; $54.47 \%$ in the cerebellum; $2.26 \%$ in abdominal lipoma; $25 \%$ in periocular lipoma; and $35.96 \%$ in the spleen. The mutation was not detected in the blood, heart, and liver.

\section{Discussion}

It has been estimated that $8 \%-35 \%$ of the brain cells carrying somatic mutations are sufficient to make one-half of the cerebral cortex dysfunctional and that, consequently, even a minority of cells with a somatic mutation can functionally disrupt widespread cortical circuits. ${ }^{23}$

In the currently accepted pathogenic mechanism for FCDII and HME, early occurring mutations affecting a progenitor cell in the ventricular zone are associated with HME, whereas late occurring mutations cause FCD. ${ }^{23}$ Seizures may persist or relapse in up to $40 \%$ of patients treated with focal resections for FCD and usually originate from the incompletely removed neighboring dysplastic cortex. ${ }^{8}$

In the attempt to control seizures originating from the area of FCD, patients 1 and 2 underwent sequential, increasingly invasive surgical procedures ultimately resulting in complete hemispherectomy. However, although no residual dysplastic tissue was detectable at MRI after hemispherectomy, after 3-8 months, both children manifested focal seizures unexpectedly 


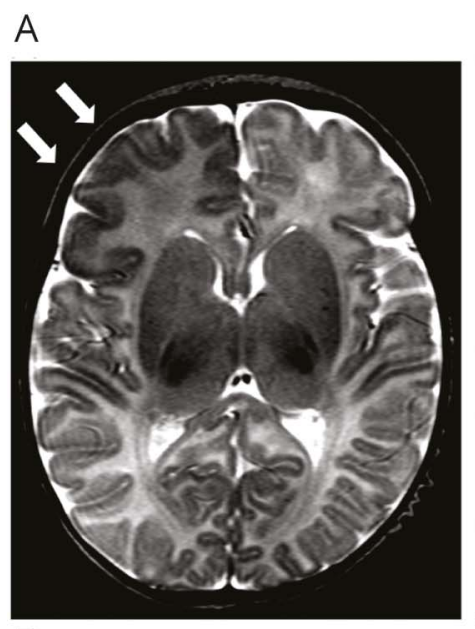

D

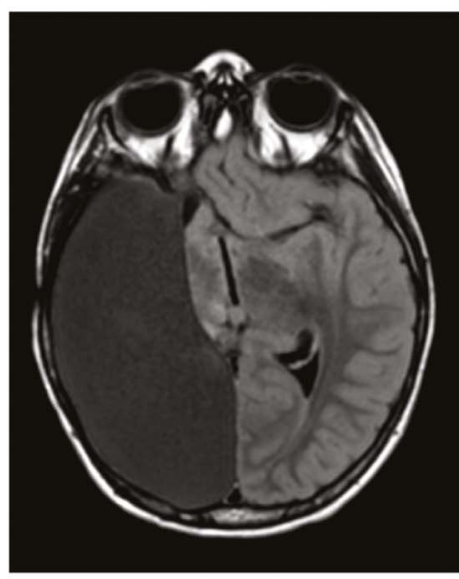

B

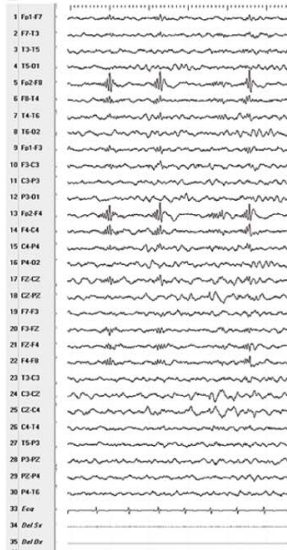

E

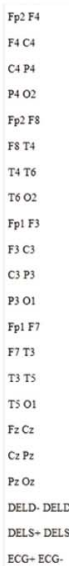

DELS+DELS.

F

NeuN
C

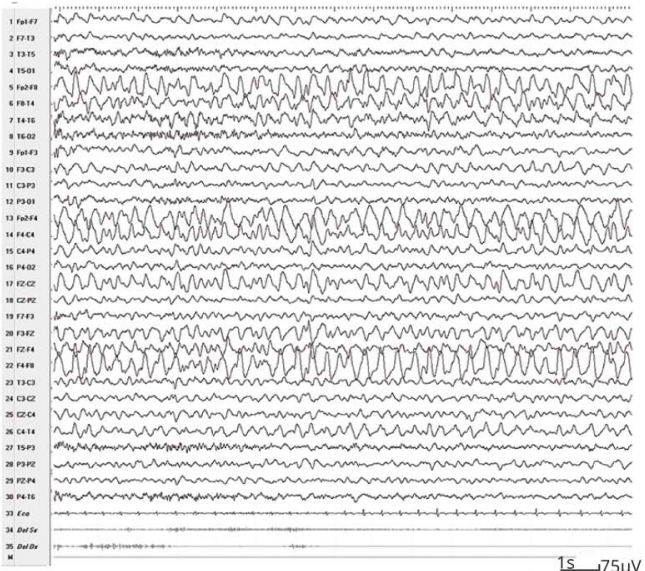

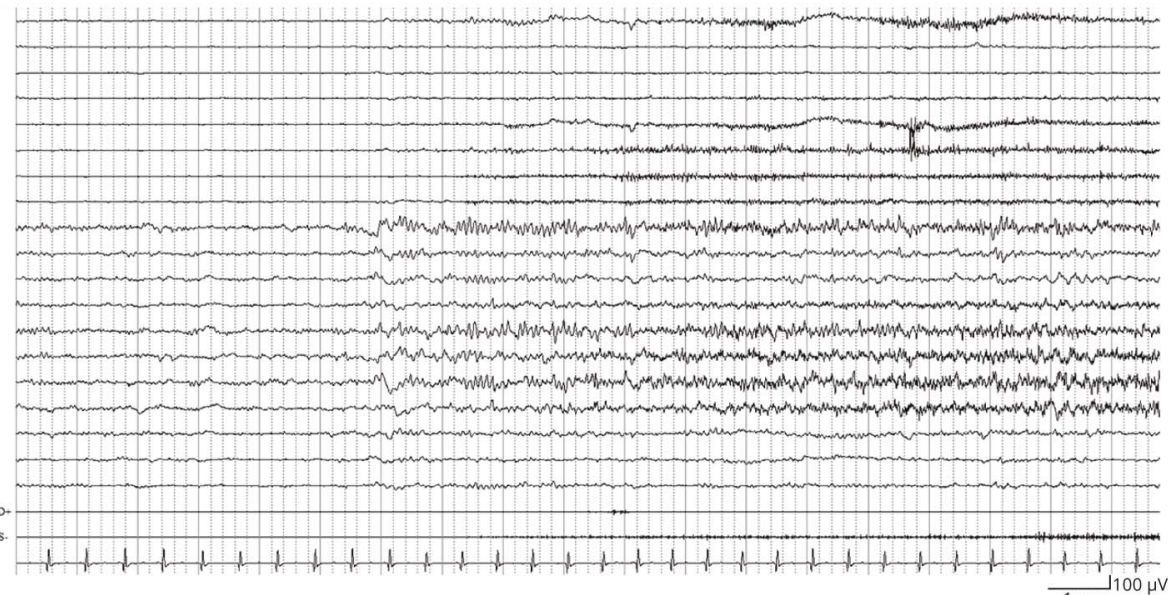

MAP2

p56

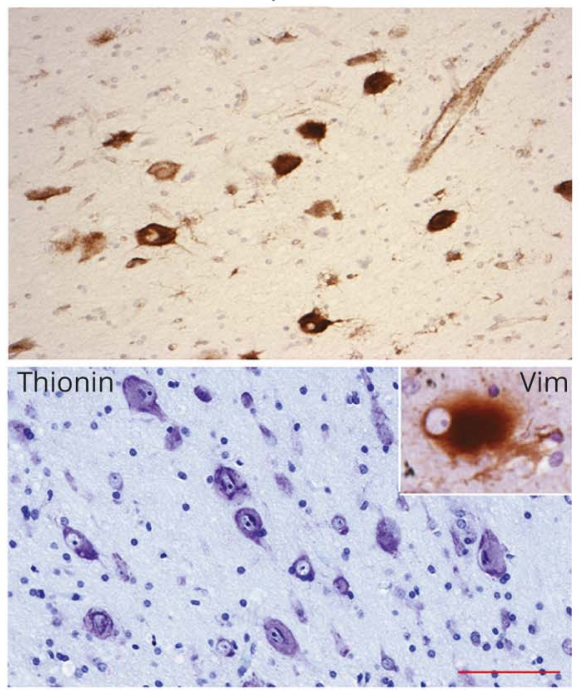

(A) Axial T2-weighted MRI section showing an extensive area of cortical dysplasia involving the right frontal lobe (arrows). (B and C) EEG recording at 3 years of life, showing subcontinuous right frontotemporal polyspikes (B), followed by a right frontal ictal discharge. (D) Axial T1-weighted MRI section after complete anatomic hemispherectomy. (E) EEG recording at 7 years shows a left frontotemporal ictal discharge. (F) Representative immunostaining of dysplastic brain tissue from the right frontal lobe showing cortical dyslamination (NeuN), dysmorphic neurons (MAP2, thionin, black arrows) with mTOR hyperactivation (pS6), and balloon cells (vimentin). Scale bar for NeuN and MAP2 $=370 \mu \mathrm{m}, \mathrm{pS} 6$ and thionin $=60 \mu \mathrm{m}$, and vimentin (inset) $=35 \mu \mathrm{m}$. MAP2 $=$ microtubule-associated protein 2; NeuN = neuronal nuclei; pS6 = phosphorylated RPS6. 


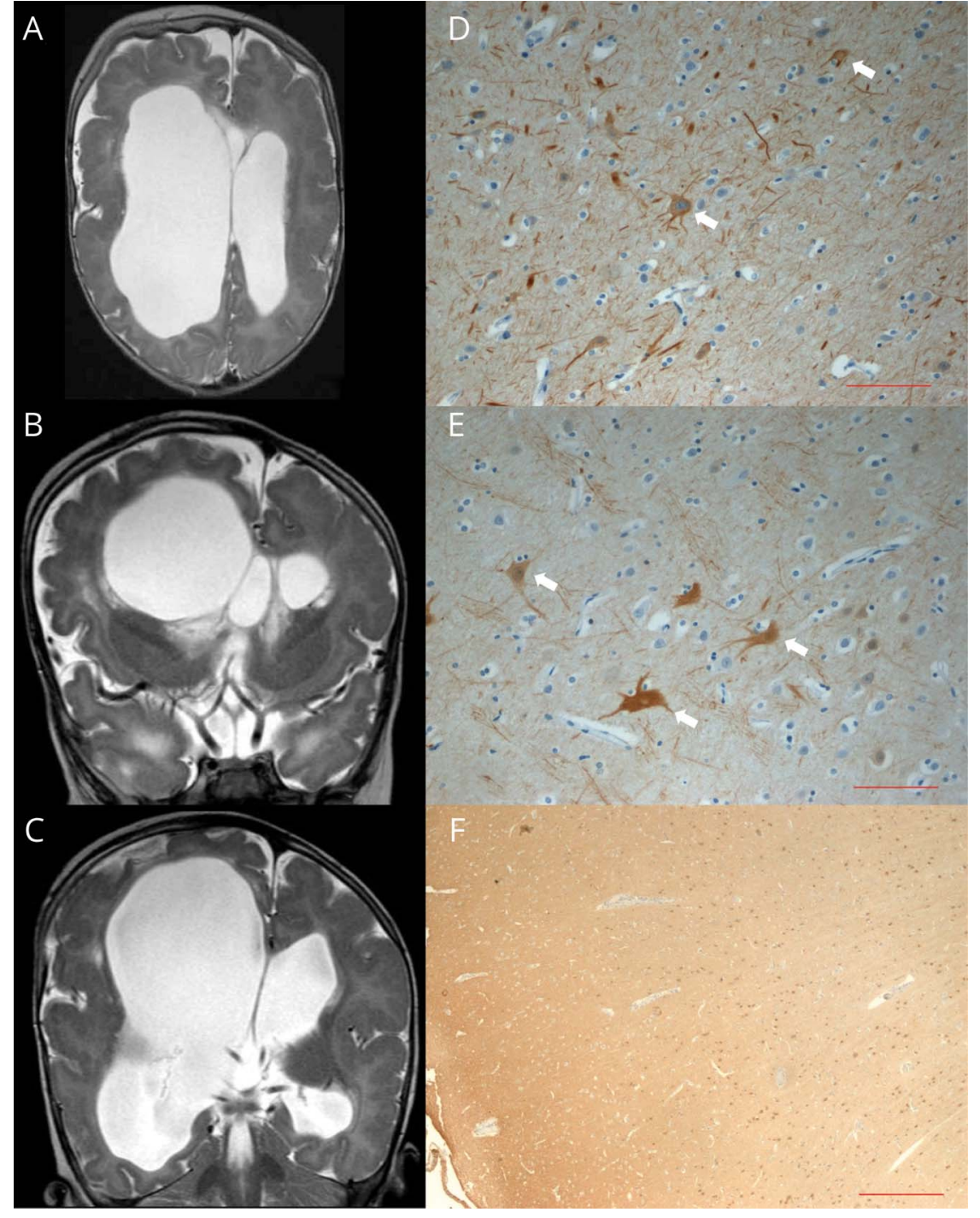

(A) Axial and (B and C) coronal T2-weighted MRI images showing asymmetric dysplastic megalencephaly. The right hemisphere has a larger volume with more severe ventricular dilatation and a larger temporal lobe; the gyral pattern is very irregular on both sides with extensive areas of polymicrogyria, cortical thickening, and infoldings. (D and E) Antineurofilament (NF) staining performed in samples from (D) the left temporal and (E) right occipital lobes showing cytomegalic neurons with disarrayed extensions (white arrows). (F) Anti-NEU-N staining showing cortical dyslamination. Scale bar for NF $=100 \mu \mathrm{m}$. Scale bar for NEU-N = $500 \mu \mathrm{m}$. NeuN = neuronal nuclei. originating from the contralateral, residual hemisphere. More than 1 hypothesis may be formulated to explain this uncommon occurrence.

One possibility is that the MTOR mutation originated before hemispheric cleavage in a site which favored its passing asymmetrically to daughter cells on either side, with only 1 hemisphere receiving a number of mutated cells large enough to develop a macroscopically visible dysplasia. Mutant cells in the contralateral hemisphere, not sufficient in the number to determine an MRI-visible malformation, would become epileptogenic later because of their small critical mass, after removal of the overwhelmingly epileptogenic contralateral dysplasia (figure 4). Different studies exploring the causes of hemispheric shift of epileptogenicity after surgery for large dysplasias, or more in general the causes of surgical failures, had already demonstrated structural abnormalities that escaped early neuroimaging or even macroscopic autoptic neuropathologic studies. ${ }^{24-26}$ In one of these studies, conducted before molecular genetic testing of brain tissue was feasible, the authors hypothesized bilateral asymmetric hemispheric abnormalities to be caused by somatic mutations affecting each developing cerebral hemisphere differently with more neurons than expected on the HME side. ${ }^{26}$

A direct correlation between somatic mutation load and brain phenotype severity has been demonstrated for FCD-related genes. A mutation gradient with an epicenter in the most epileptogenic area has been found in the dysplastic tissue in a patient carrying the p.Ser2215Phe MTOR mutation. ${ }^{3}$ Similar indications arise from the demonstration that, in a patient carrying a de novo heterozygous constitutional DEPDC5 mutation (p.Q797Argfs*18), the mutational load of a second somatic hit in the same gene (p.Arg1332*) correlated with dysmorphic neuron density in the dysplastic tissue. ${ }^{27}$ Finally, mutations in SLC35A2, at AAF $\sim 6 \%$, cause radiographically 
Figure 4 Schematic representation of the mechanisms that would lead to asymmetric distribution of mutant cells in the brain hemispheres

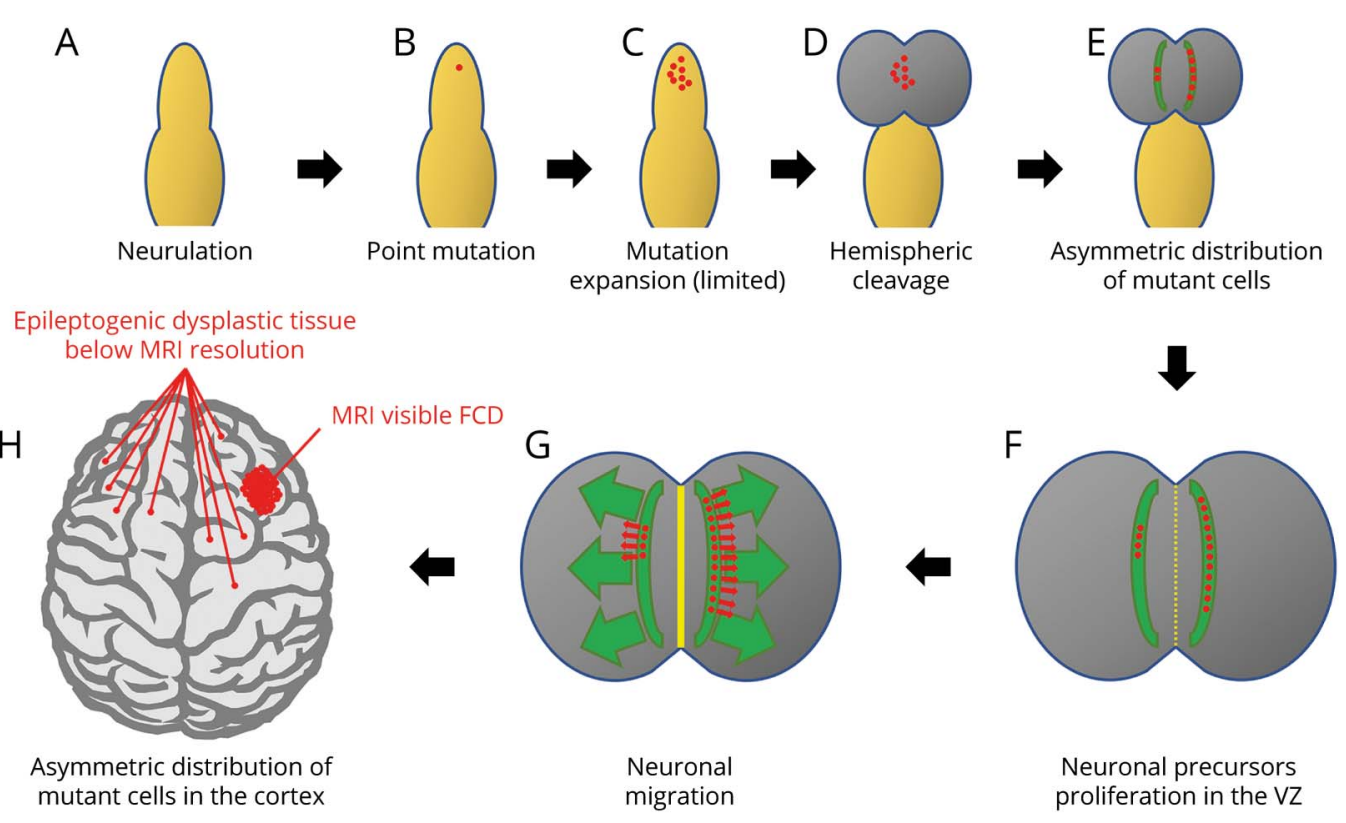

After neurulation (A), a single point mutation occurs in a neuronal progenitor (B) and is passed to a limited number of daughter cells (C). At hemispheric cleavage (D), mutant cells migrate in the 2 hemispheres in different proportions because of their asymmetric initial distribution (E). After neuronal proliferation in the ventricular zone (VZ) (F), and neuronal migration (G), the asymmetric distribution of mutant cells in the 2 hemispheres causes a visible area of cortical dysplasia where the concentration of mutant cells is higher and only small foci of dysplastic tissue below MRI resolution where the percentage of mutant cells is very low $(\mathrm{H})$. Note that even in the hemisphere harboring the main area of cortical dysplasia, mutant cells are present outside the limits of the visible abnormality and are the cause of seizure recurrence after surgery. FCD = focal cortical dysplasia.

nonlesional focal epilepsy, whereas at AAF 22\% cause mild malformations of cortical development. ${ }^{28,29}$

The MTOR mutations we identified in patients 1 and 2 (p.Ser2215Phe and p.Leu1460Pro) belong to the subset of recurrent mutations found at low-level somatic mosaicism in

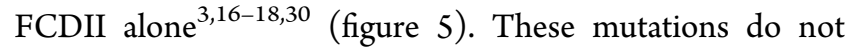
occur as constitutional likely because they are not viable. Rodent's neurons transfected independently with p.Ser2215Phe, p.Leu1460Pro, or p.Ser2215Tyr exhibit a much stronger increase of mTORC1 activity than that induced by transfection with mutations causing HME or MEG (i.e., p.Glu1799Lys, p.Thr1977Ile, and p.Cys1483Tyr). ${ }^{3}$ It is therefore conceivable that p.Ser2215Phe and p.Leu1460Pro may precipitate epileptogenic activity even at very low AAF levels due to strong mTORC1 activation.

The observation that in patient 3 the p.Glu17Lys $A K T 1$ mutation occurred in the 2 asymmetrically dysplastic hemispheres at AAF levels that correlated with anatomic severity further supports the hypothesis that mutations occurring before hemispheric cleavage should be counted among the pathogenic mechanisms underlying bilateral asymmetric brain dysplasia and dissociated epileptogenesis.

An alternative hypothesis to explain seizure onset in the seemingly intact hemisphere is that a second somatic mutational hit has occurred in it, involving a different mTOR pathway gene or any of many other epilepsy genes. This second hit, not present in the resected dysplastic tissue, would be sufficient to activate epileptogenesis but not to determine an MRI-visible malformation. We had previously demonstrated how a somatic MTOR mutation in the dysplastic hemisphere and a systemic mosaic RPS6 mutation synergistically concurred in determining a HME/ epilepsy phenotype in which seizure onset had occurred in the seemingly intact hemisphere after hemispherectomy. ${ }^{20}$ We could not exclude, however, that the MTOR mutation was also present, albeit with lower AAF ratios, in the nondysplastic hemisphere.

Follow-up studies on a sufficiently large number of operated patients, and a systematic search of somatic mutations in surgical specimens, will clarify the long-term risk of recurrence of seizures arising from the residual homolateral dysplasia or contralateral cortex with respect to specific somatic mutations affecting MTOR or mTOR pathway genes. For now, our observations suggest that, in case of seizure recurrence, repeated surgeries up to complete hemispherectomy should be very carefully weighted in children in whom a somatic mutation in MTOR is demonstrated after a first operation, as its distribution and cellular consequences can be misleading.

\section{Acknowledgment}

The authors thank the patients and their families for participating in their research. 
Figure 5 Schematic representation of the different possible combinations between specific MTOR mutations, mutant cells distribution, malformations of cortical development, and epileptogenesis

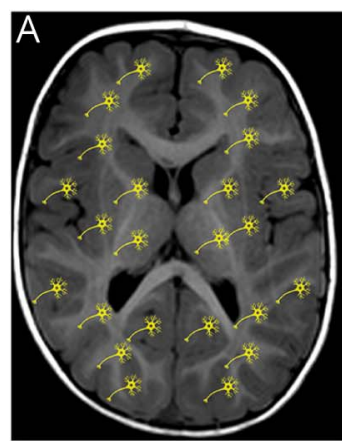

Constitutional/systemic mosaic with homogeneous distribution in the hemispheres

MEG

Focal or generalized epilepsy

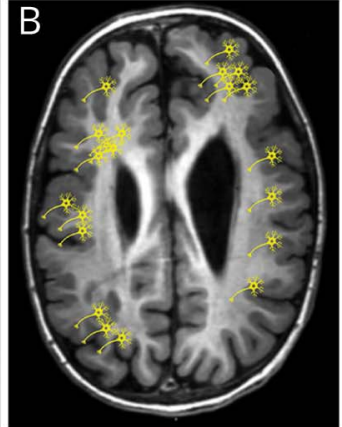

Systemic mosaic with bilateral uneven distribution or multifoca epilepsy

p.Th1977lle (20-55)**

Gln962Arg

p.Cys1483Phe

p.Trp1490Arg

p.Met1595Ile

p.Glu1799Lys*

p.Ala1832Thr

p.Phe1888Cys

p.Phe2202Cys

p.Met2327Ile

p.Asp2412Val

p.lle2501Val

p.Arg2505Pro

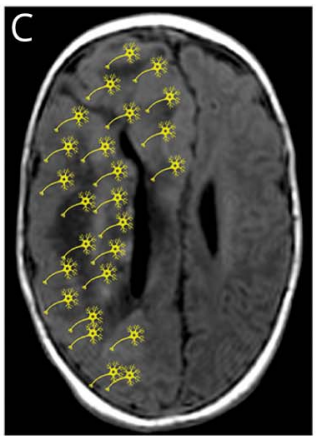

Somatic with unilateral multilobar distribution Usually unilateral
epilepsy syndrome

p.Ala1669Ser (44) p.Cys1483Tyr (8-36) ***

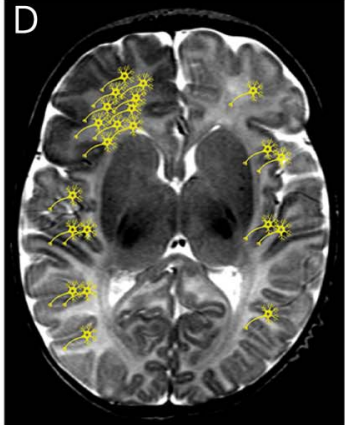

Somatic with grossly unbalanced hemispheric distribution and strong elevation of mTORC1 activity

FCDIla/b Bilateral independent seizures onset

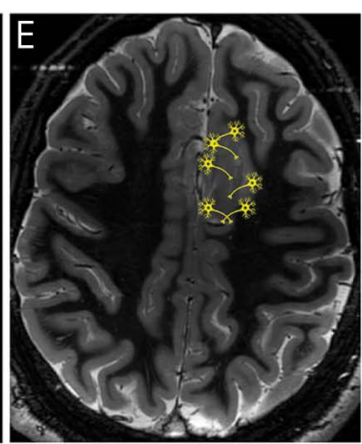

Somatic affecting one area of FCD

FCDIla/b Focal epilepsy

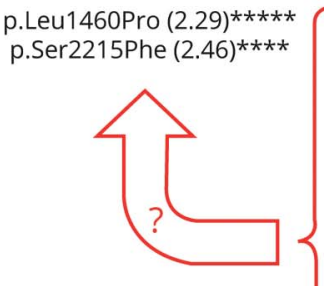

p.Arg624His (1.26)

p.Tyr1450Asp (3.76)

p.Trp1456Gly (7-8)

p.Ala1459Asp (1.4-1.65) p.Leu1460Pro $(1.59-6)^{\star * * * *}$ p.Cys1483Arg (6.61-9.77) p.Cys1483Tyr (3) $)^{\star \star *}$

p.Arg1709His (4.41) p.Thr1977Lys (1.51-2.93) p.Arg2193Cys (3.48-7.28) p.Ser2215Phe $(0.93-8.6)^{* * * *}$

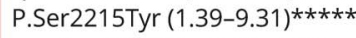
p.Leu2427GIn (2.86-5.11) p.Leu2427Pro (6.57-12.63)

Asterisks indicate mutations whose hyperactivation properties have been tested in parallel in functional studies; the number of asterisks reflects the level of MTOR hyperactivation observed. ${ }^{3}$ (A) Constitutional and systemic mosaic mutations resulting in homogeneous and widespread distribution of mutant cells in both hemispheres cause diffuse cortical malformations, with focal or generalized epilepsy of variable severity. These mutations are supposed, or have been demonstrated, to be moderately hyperactivating. (B) Systemic mosaic mutations may also cause mutant cells to be unevenly distributed in the brain hemispheres and cause a gross bilateral asymmetric malformation in which they are, however, present in both hemispheres. The only mutation associated with this phenotype has been functionally tested and has shown intermediate hyperactivating properties. (C) Somatic mutations with unilateral multilobar distribution cause hemimegalencephaly or large multilobar dysplasia and epilepsy, a syndrome which is usually unilateral. (D) Somatic mutations with strong mTORC1 activation, such as those identified in patients 1 and 2, have been associated with FCDII and intractable ipsilateral focal seizures at onset. Onset of contralateral seizures after the hemisphere harboring the FCD was removed strongly suggests a grossly unbalanced hemispheric distribution with foci of mutant cells being also present contralaterally and capable of generating seizures at some point. (E) Somatic mutations with low levels of mosaicism affecting 1 hemisphere cause FCDII and focal epilepsy as it was the case in (D) before hemispherectomy. These mutations tend to be highly hyperactivating, and if present at even very low AAF in the contralateral hemisphere might cause contralateral epileptogenesis at some point. Whether a critical mass of mutated cells or a certain level of aggregation also influences their epileptogenic potential remains unknown. A circumscribed distribution of MTOR mutations and dysplastic epileptogenic tissue as represented in (E) remains the most desirable eventuality because, as demonstrated by the need for progressively larger resections in patients 1 and 2 (the latter represented in (D)), even in (E) dysplastic cells might also be widely distributed within the hemisphere harboring the visible dysplasia and cause persisting-relapsing seizures after focal resection. Mutational data have been extracted from OMIM (omim.org/entry/601231) and HGMD professional (portal.biobase-international.com) databases. Numbers in parentheses represent the range of mosaicism percentage identified for each mutation. AAF = alternative allele fraction; DMEG = dysplastic megalencephaly; FCDII = focal cortical dysplasia type II; HME = hemimegalencephaly; MEG = megalencephaly; $\mathrm{mTOR}=$ mammalian target of rapamycin.

\section{Study funding}

The Italian Ministry of Health and the Tuscany Region (RF2013-02355240) to R. Guerrini, AICE-FIRE 2017, Project "Identifying the most effective MTOR pathway inhibitor in vitro: A first step towards personalized treatment options in patients with developmental brain disorders, intractable epilepsy, and cognitive impairment” to R. Guerrini.

\section{Disclosure}

The authors report no disclosures relevant to the manuscript. Go to Neurology.org/NG for full disclosures.

\section{Publication history}

Received by Neurology: Genetics May 24, 2020. Accepted in final form October 21, 2020. 
Appendix Authors

\begin{tabular}{|c|c|c|}
\hline Name & Location & Contribution \\
\hline $\begin{array}{l}\text { Renzo } \\
\text { Guerrini, } \\
\text { MD, FRCP }\end{array}$ & $\begin{array}{l}\text { Pediatric Neurology, } \\
\text { Neurogenetics and } \\
\text { Neurobiology Unit and } \\
\text { Laboratories, Children's } \\
\text { Hospital A. Meyer, University } \\
\text { of Florence, Italy }\end{array}$ & $\begin{array}{l}\text { Study concept and } \\
\text { design; study } \\
\text { supervision; acquisition } \\
\text { and interpretation of } \\
\text { data; drafting and critical } \\
\text { revision of the } \\
\text { manuscript for } \\
\text { important intellectual } \\
\text { content; and obtained } \\
\text { funding }\end{array}$ \\
\hline
\end{tabular}

\begin{tabular}{lll}
\hline $\begin{array}{l}\text { Mara } \\
\text { Cavallin, } \\
\text { MD, PhD }\end{array}$ & $\begin{array}{l}\text { Pediatric Neurology, } \\
\text { Neurogenetics and } \\
\text { Neurobiology Unit and } \\
\text { Laboratories, Children's } \\
\text { Hospital A. Meyer, University } \\
\text { of Florence, Italy }\end{array}$ & $\begin{array}{l}\text { Study concept and } \\
\text { design; acquisition and } \\
\text { interpretation of data; } \\
\text { and drafting the } \\
\text { manuscript }\end{array}$ \\
\hline $\begin{array}{l}\text { Tommaso } \\
\text { Pippucci, } \\
\text { PhD }\end{array}$ & $\begin{array}{l}\text { Medical Genetics Unit, } \\
\text { Sant'Orsola-Malpighi }\end{array}$ & $\begin{array}{l}\text { Patient 2 bioinformatic } \\
\text { data analysis and } \\
\text { University Hospital, Bologna, }\end{array}$ \\
& Italy & $\begin{array}{l}\text { manuscript } \\
\text { mane }\end{array}$
\end{tabular}

Anna Rosati, Pediatric Neurology,

MD, PhD Neurogenetics and

Neurobiology Unit and

Laboratories, Children's

Hospital A. Meyer, University

of Florence, Italy

\begin{tabular}{|c|c|c|}
\hline $\begin{array}{l}\text { Francesca } \\
\text { Bisulli, MD }\end{array}$ & $\begin{array}{l}\text { IRCCS Bologna Institute for } \\
\text { Neurological Sciences, } \\
\text { Bologna, Italy. Member of } \\
\text { ERN EpiCARE }\end{array}$ & $\begin{array}{l}\text { Patient } 2 \text { data collection } \\
\text { and revision of the } \\
\text { manuscript }\end{array}$ \\
\hline $\begin{array}{l}\text { Paola } \\
\text { Dimartino, } \\
\text { MSc }\end{array}$ & $\begin{array}{l}\text { Department of Medical and } \\
\text { Surgical Sciences, University } \\
\text { of Bologna, Bologna, Italy }\end{array}$ & Patient 2 genetic analysis \\
\hline $\begin{array}{l}\text { Carmen } \\
\text { Barba, MD, } \\
\text { PhD }\end{array}$ & $\begin{array}{l}\text { Pediatric Neurology, } \\
\text { Neurogenetics and } \\
\text { Neurobiology Unit and } \\
\text { Laboratories, Children's } \\
\text { Hospital A. Meyer, University } \\
\text { of Florence, Italy }\end{array}$ & $\begin{array}{l}\text { Patients } 1 \text { and } 3 \text { data } \\
\text { collection and revision of } \\
\text { the manuscript }\end{array}$ \\
\hline $\begin{array}{l}\text { Rita } \\
\text { Garbelli, } \\
\text { PhD }\end{array}$ & $\begin{array}{l}\text { Clinical Epileptology and } \\
\text { Experimental } \\
\text { Neurophysiology Unit, IRCCS } \\
\text { Istituto Neurologico C. Besta, } \\
\text { Milan, Italy }\end{array}$ & $\begin{array}{l}\text { Histopathology in } \\
\text { patient } 2\end{array}$ \\
\hline $\begin{array}{l}\text { Anna Maria } \\
\text { Buccoliero, } \\
\text { MD, PhD }\end{array}$ & $\begin{array}{l}\text { Pathology Unit, Children's } \\
\text { Hospital A. Meyer-University } \\
\text { of Florence, Italy }\end{array}$ & $\begin{array}{l}\text { Histopathology in } \\
\text { patient 1; and autopsy } \\
\text { and histopathology in } \\
\text { patient } 3\end{array}$ \\
\hline $\begin{array}{l}\text { Laura Tassi, } \\
\text { MD }\end{array}$ & $\begin{array}{l}\text { "C. Munari” Epilepsy Surgery } \\
\text { Center, Niguarda, Hospital, } \\
\text { Milan, Italy }\end{array}$ & $\begin{array}{l}\text { Patient } 2 \text { data collection } \\
\text { and revision of the } \\
\text { manuscript }\end{array}$ \\
\hline $\begin{array}{l}\text { Valerio } \\
\text { Conti, PhD }\end{array}$ & $\begin{array}{l}\text { Pediatric Neurology, } \\
\text { Neurogenetics and } \\
\text { Neurobiology Unit and } \\
\text { Laboratories, Children's } \\
\text { Hospital A. Meyer, University } \\
\text { of Florence, Italy }\end{array}$ & $\begin{array}{l}\text { Study concept and } \\
\text { design; genetic testing } \\
\text { and data analysis in } \\
\text { patients } 1 \text { and } 3 \text {; and } \\
\text { drafting the manuscript }\end{array}$ \\
\hline
\end{tabular}

\section{References}

1. Lipton JO, Sahin M. The neurology of mTOR. Neuron 2014;84:275-291.
2. Jansen LA, Mirzaa GM, Ishak GE, et al. PI3K/AKT pathway mutations cause a spectrum of brain malformations from megalencephaly to focal cortical dysplasia. Brain 2015;138:1613-1628.

3. Mirzaa GM, Campbell CD, Solovieff N, et al. Association of MTOR mutations with developmental brain disorders, including megalencephaly, focal cortical dysplasia, and pigmentary mosaicism. JAMA Neurol 2016;73:836-845.

4. D'Gama AM, Woodworth MB, Hossain AA, et al. Somatic mutations activating the mTOR pathway in dorsal telencephalic progenitors cause a continuum of cortical dysplasias. Cell Rep 2017;21:3754-3766.

5. Sim JC, Scerri T, Fanjul-Fernández M, et al. Familial cortical dysplasia caused by mutation in the mammalian target of rapamycin regulator NPRL3. Ann Neurol 2016; 79:132-137.

6. Baldassari S, Ribierre T, Marsan E, et al. Dissecting the genetic basis of focal cortical dysplasia: a large cohort study. Acta Neuropathol 2019;138:885-900.

7. Baldassari S, Picard F, Verbeek NE, et al. The landscape of epilepsy-related GATOR1 variants. Genet Med 2019;21:398-408.

8. Guerrini R, Duchowny M, Jayakar P, et al. Diagnostic methods and treatment options for focal cortical dysplasia. Epilepsia 2015;56:1669-1686.

9. Ramírez-Molina JL, Di Giacomo R, Mariani V, et al. Surgical outcomes in two different age groups with focal cortical dysplasia type II: any real difference? Epilepsy Behav 2017;70:45-49.

10. Choi SA, Kim SY, Kim H, et al. Surgical outcome and predictive factors of epilepsy surgery in pediatric isolated focal cortical dysplasia. Epilepsy Res 2018; 139:54-59.

11. Engel J. Update on surgical treatment of the epilepsies: summary of the Second International Palm Desert Conference on the Surgical Treatment of the Epilepsies (1992). Neurology 1993;43:1612.

12. Barba C, Parrini E, Coras R, et al. Co-occurring malformations of cortical development and SCN1A gene mutations. Epilepsia 2014;55:1009-1019.

13. Strauss KA, Puffenberger EG, Huentelman MJ, et al. Recessive symptomatic focal epilepsy and mutant contactin-associated protein-like 2. N Engl J Med 2006;354: 1370-1377.

14. Stevelink R, Sanders MWCB, Tuinman MP, et al. Epilepsy surgery for patients with genetic refractory epilepsy: a systematic review. Epileptic Disord 2018;20 99-115.

15. Fisher RS, Cross JH, French JA, et al. Operational classification of seizure types by the international league against epilepsy: position paper of the ILAE Commission for Classification and Terminology. Epilepsia 2017;58:522-530.

16. Lim JS, Kim WI, Kang HC, et al. Brain somatic mutations in MTOR cause focal cortical dysplasia type II leading to intractable epilepsy. Nat Med 2015;21: 395-400.

17. Nakashima M, Saitsu H, Takei N, et al. Somatic Mutations in the MTOR gene cause focal cortical dysplasia type IIb. Ann Neurol 2015;78:375-386.

18. Leventer RJ, Scerri T, Marsh APL, et al. Hemispheric cortical dysplasia secondary to a mosaic somatic mutation in MTOR. Neurology 2015;84:2029-2032.

19. Dimartino P, Mariani V, Marconi C, et al. Accurate detection of hot-spot MTOR somatic mutations in archival surgical specimens of focal cortical dysplasia by molecular inversion probes. Mol Diagn Ther 2020;24:571-577.

20. Pelorosso C, Watrin F, Conti V, et al. Somatic double-hit in MTOR and RPS6 in hemimegalencephaly with intractable epilepsy. Hum Mol Genet 2019;28: 3755-3765.

21. de Palma L, Pietrafusa N, Gozzo F, et al. Outcome after hemispherotomy in patients with intractable epilepsy: comparison of techniques in the Italian experience. Epilepsy Behav 2019;93:22-28.

22. Lindhurst MJ, Sapp JC, Teer JK, et al. A mosaic activating mutation in AKT1 associated with the Proteus syndrome. N Engl J Med 2011;365:611-619.

23. Poduri A, Evrony GD, Cai X, Walsh CA. Somatic mutation, genomic variation, and neurological disease. Science 2013;341:1237758.

24. Kometani H, Sugai K, Saito Y, et al. Postnatal evolution of cortical malformation in the "non-affected" hemisphere of hemimegalencephaly. Brain Dev 2010 $32: 412-416$

25. Jahan R, Mischel PS, Curran JG, Peacock WJ, Shields DW, Vinters HV. Bilateral neuropathologic changes in a child with hemimegalencephaly. Pediatr Neurol 1997; 17:344-349.

26. Salamon N, Andres M, Chute DJ, et al. Contralateral hemimicrencephaly and clinical-pathological correlations in children with hemimegalencephaly. Brain 2006; 129:352-365.

27. Lee WS, Stephenson SEM, Howell KB, et al. Second-hit DEPDC5 mutation is limited to dysmorphic neurons in cortical dysplasia type IIA. Ann Clin Transl Neurol 2019;6: $1338-1344$.

28. Heinzen EL. Somatic variants in epilepsy: advancing gene discovery and disease mechanisms. Curr Opin Genet Dev 2020;65:1-7.

29. Winawer MR, Griffin NG, Samanamud J, et al. Somatic SLC35A2 variants in the brain are associated with intractable neocortical epilepsy. Ann Neurol 2018;83: 1133-1146.

30. Møller RS, Weckhuysen S, Chipaux M, et al. Germline and somatic mutations in the MTOR gene in focal cortical dysplasia and epilepsy. Neurol Genet 2016;2 e118. 


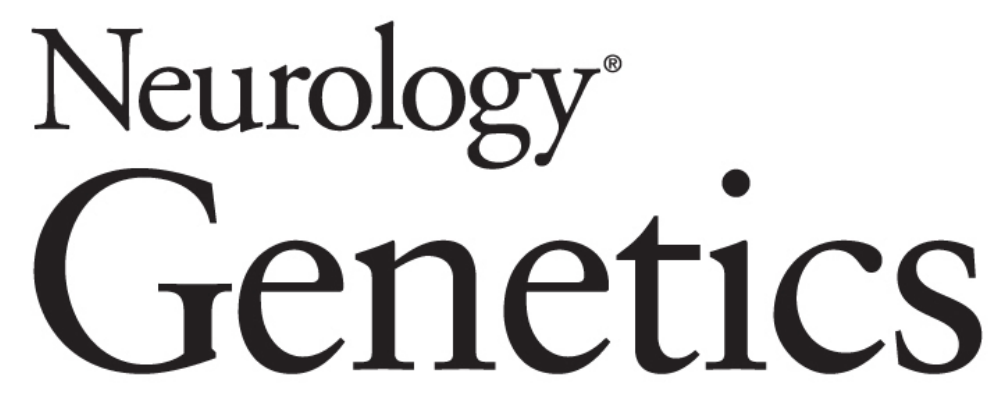

Is Focal Cortical Dysplasia/Epilepsy Caused by Somatic MTOR Mutations Always a Unilateral Disorder?

Renzo Guerrini, Mara Cavallin, Tommaso Pippucci, et al.

Neurol Genet 2021;7;

DOI 10.1212/NXG.0000000000000540

This information is current as of December 9, 2020

Neurol Genet is an official journal of the American Academy of Neurology. Published since April 2015, it is an open-access, online-only, continuous publication journal. Copyright Copyright $\odot 2020$ The Author(s). Published by Wolters Kluwer Health, Inc. on behalf of the American Academy of Neurology.. All rights reserved. Online ISSN: 2376-7839.

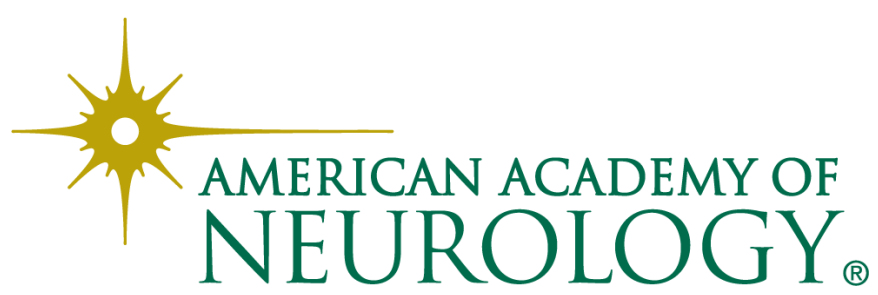




\section{Updated Information \& Services}

References

Citations

Subspecialty Collections

Permissions \& Licensing

\section{Reprints}

including high resolution figures, can be found at: http://ng.neurology.org/content/7/1/e540.full.html

This article cites 30 articles, 2 of which you can access for free at: http://ng.neurology.org/content/7/1/e540.full.html\#\#ref-list-1

This article has been cited by 2 HighWire-hosted articles: http://ng.neurology.org/content/7/1/e540.full.html\#\#otherarticles

This article, along with others on similar topics, appears in the following collection(s):

\section{All Genetics}

http://ng.neurology.org//cgi/collection/all_genetics

Cohort studies

http://ng.neurology.org//cgi/collection/cohort_studies

Diagnostic test assessment

http://ng.neurology.org//cgi/collection/diagnostic_test_assessment_ Inclusion, Diversity, Equity, Anti-racism, and Social Justice

\section{(IDEAS)}

http://ng.neurology.org//cgi/collection/all_equity_diversity_and_inclusi on

Muscle disease

http://ng.neurology.org//cgi/collection/muscle_disease

Information about reproducing this article in parts (figures,tables) or in its entirety can be found online at:

http://ng.neurology.org/misc/about.xhtml\#permissions

Information about ordering reprints can be found online: http://ng.neurology.org/misc/addir.xhtml\#reprintsus

Neurol Genet is an official journal of the American Academy of Neurology. Published since April 2015, it is an open-access, online-only, continuous publication journal. Copyright Copyright $\odot 2020$ The Author(s). Published by Wolters Kluwer Health, Inc. on behalf of the American Academy of Neurology.. All rights reserved. Online ISSN: 2376-7839.

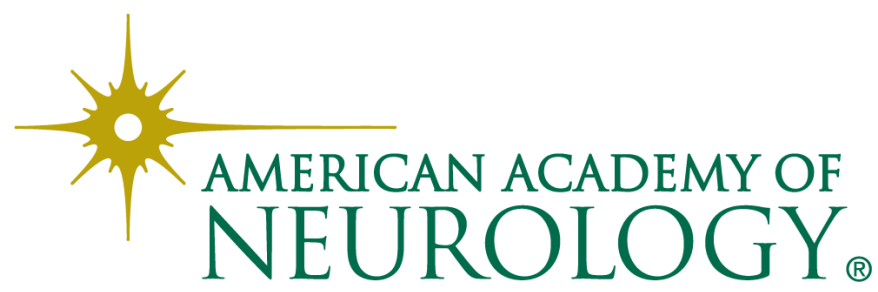

